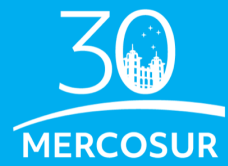

$$
\begin{array}{c|l}
++ \\
+ & \begin{array}{l}
\text { TPR } \\
\text { Tribunal Permanente } \\
\text { de Revisão }
\end{array}
\end{array}
$$

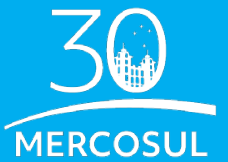

\title{
Série Jurisprudência LAUDOS $N^{\circ} 3$, Julho 2021
}

LAUDO No 02/2006

Recurso de Revisão apresentado pela República Argentina contra a decisão do Tribunal Arbitral Ad Hoc, de 21 de junho de 2006. "Impedimentos Impostos à Livre Circulação pelas Barreiras em Território Argentino de Vias de Acesso às Pontes Internacionais Gral. San Martin e Gral. Artigas"
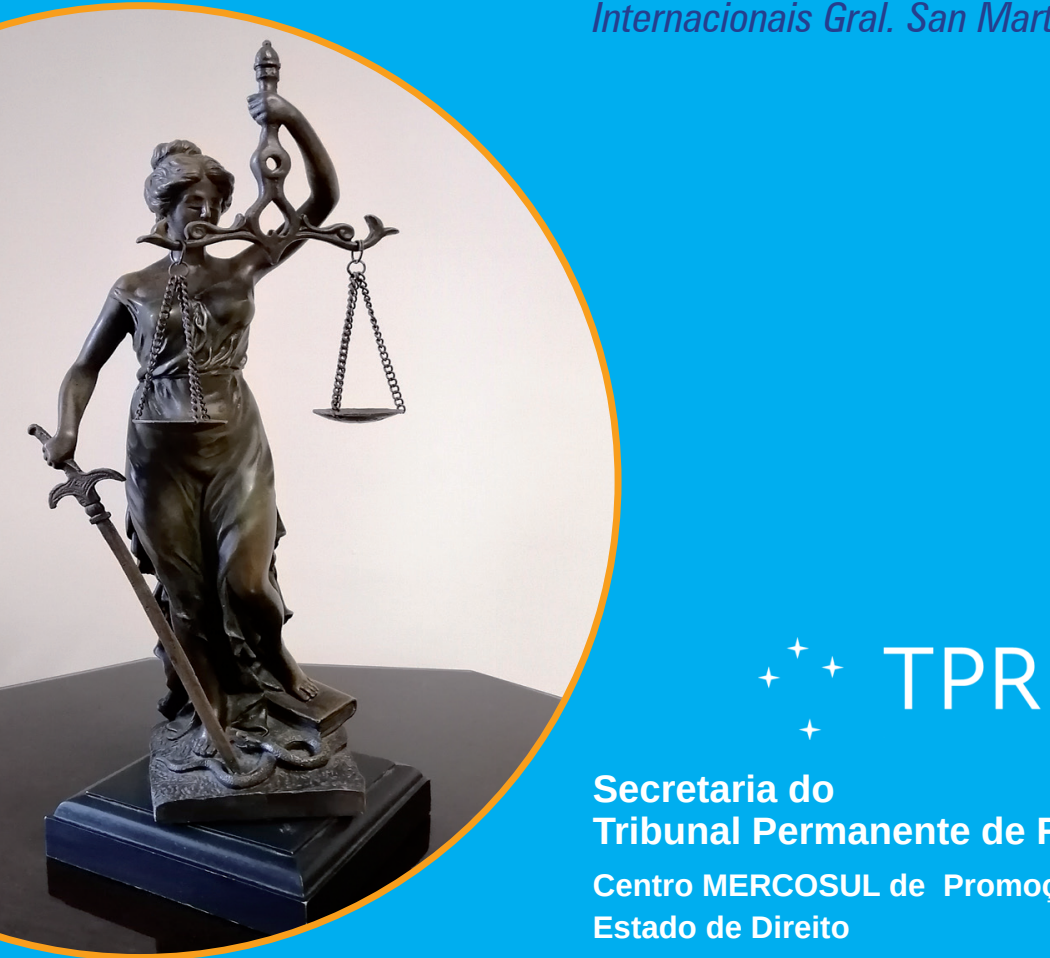

Secretaria do Tribunal Permanente de Revisão Centro MERCOSUL de Promoção de Estado de Direito 
Secretaria do Tribunal Permanente de Revisão Secretário: Juan Manuel Rivero Godoy

Equipe de trabalho:

Brenda Maffei

Maider Méndez

Renata Cenedesi

Manuel Fernández

Secretaria do Tribunal Permanente de Revisão.

Centro MERCOSUL de Promoção de Direito 


\title{
FICHA CATALOGRÁFICA
}

\begin{abstract}
Classificação. 341.2458 Secretaria do Tribunal Permanente de Revisão.
SE446 I Centro Mercosul de Promoção de Estado de Direito

LAUDO N. 02/2006: Recurso de revisão apresentado pela República Argentina contra a decisão do TAH de 21 de junho de 2006, constituído para entender na controvérsia promovida pela República Oriental do Uruguai contra a República Argentina sobre "impedimentos à livre circulação derivado dos cortes no território argentino das vias de acesso às pontes internacionais Gral. San Martín e Gral Artigas." / Centro MERCOSUL de Promoção de Estado de Direito; Ed. Assunção: Secretaria do Tribunal Permanente de Revisão, 2021
\end{abstract}

14 p.; 22,4 x 15,4 cm. (Laudos $\mathrm{n}^{\circ} 3$ ) ISSN:

1. Direito internacional. 2. Integração regional. 3. Mercosul. 4. Recursos. 5. Liberdade de circulação. 6. Cortes de rotas. I. Título. II. Autor

Sob términos de licença Creative commons 4.0

Secretaria do Tribunal Permanente de Revisão. Centro MERCOSUL de Promoção de Estado de Direito.

Assunção, República do Paraguai, 2021

A reprodução total ou parcial desta publicação é autorizada sempre que for citada a fonte.

A informação contida na publicação é responsabilidade exclusiva do autor/es da mesma. 


\section{Série: Jurisprudência LAUDOS $\mathrm{N} \times 3$}

\section{LAUDO N. ${ }^{\circ}$ 02/2006}

Recurso de revisão apresentado pela República Argentina contra a decisão do TAH de 21 de junho de 2006 constituído para entender na controvérsia promovida pela República Oriental do Uruguai contra a República Argentina sobre "impedimentos à livre circulação derivado dos cortes no território argentino das vias de acesso às pontes internacionais Gral. San Martín e Gral Artigas."

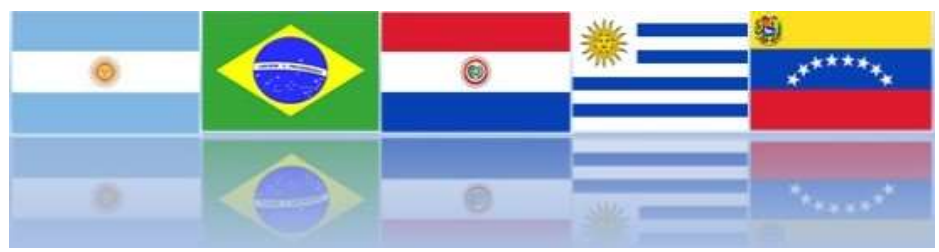

Assunção, julho 2021 


\section{Conteúdo}

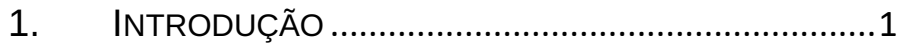

2. APRESENTAÇÃO E RESUMO GERAL DO LAUDO....2

2.1 Ficha técnica ...................................................... 2

2.2 Apresentação ................................................. 6

2.3 Resumo técnico jurídico do Laudo...................... 7

3. REFERÊNCIAS BIBLIOGRÁFICAS ....................... 10

4. GUIA DE BIBLIOGRAFIA COMPLEMENTAR ...........11 



\section{Introdução}

A Secretaria do Tribunal Permanente de Revisão apresenta uma nova publicação, um resumo técnicojurídico da série jurisprudência: sobre o terceiro laudo emitido pelo TPR, o laudo $n^{\circ}$ 2/2006 no qual anualizou sobre 0 recurso apresentado pela República Argentina contra a decisão do TAH de 21 de junho de 2006 constituído para entender na controvérsia promovida pela República Oriental do Uruguai contra a República Argentina sobre "impedimentos à livre circulação derivado dos cortes no território argentino das vias de acesso às pontes internacionais Gral. San Martín e Gral Artigas."

Este novo número feito em conjunto pelo Centro Mercosul de Promoção do Estado de Direito (CMPED), Área Jurídica, Biblioteca e Arquivo de Documentos, Secretaria e Administração e Informática e Banco de Dados da ST, é uma publicação em que o CMPED faz como principal responsável no desempenho de suas funções. ${ }^{1}$

\footnotetext{
1 1. Trabalhos de investigação relacionados com a promoção do Estado de Direito, democracia, direitos humanos e liberdades fundamentais nos processos de integração regional com ênfase no mecanismo de solução de controvérsias do Mercosul.
}

2. Difusão através da realização de cursos, conferências, seminários, foros, publicações, reuniões de acadêmicos, representantes governamentais e representantes da sociedade civil.

3. Cursos de capacitação, programas de intercâmbio, oferta de bolsas de estudo dirigidas a profissionais, em função do seu orçamento e convênios que facilitem estas atividades. 


\section{Apresentação e resumo geral do laudo}

\subsection{Ficha técnica}

LAUDO: Terceiro laudo proferido pelo Tribunal Permanente de Revisão pleiteado perante o TPR através de um recurso de revisão apresentado pela República Argentina contra a decisão do TAH de 21 de junho de 2006 na controvérsia "impedimentos à livre circulação derivado dos cortes no território argentino das vias de acesso às pontes internacionais Gral. San Martín e Gral Artigas."

DATA DE INTERPOSIÇÃO DO RECURSO:
29/06/2006

DATA DE EMISSÃO DO LAUDO: 6/07/2006

PARTES:

RECORRENTE: República Argentina

ÁRBITROS: Dr. Nicolás Eduardo Becerra (Argentina) Dr. Ricardo Olivera (Uruguay) Dr. Wilfrido Fernández

4. Um espaço na página web do TPR, para promover os trabalhos, convocatórios, cursos, seminários, congressos, etc.

5. Um espaço especializado destinado às publicações diversas que derivem do CMPED dentro da biblioteca da STPR, como também a aquisição de bibliografia específica em temas relacionados com a promoção do Estado de Direito, democracia, direitos humanos e liberdades fundamentais nos processos de integração regional, arbitragem, solução de controvérsias; com ênfase no Mercosul. 


\title{
Série: Jurisprudência * LAUDOS N. ${ }^{\circ} 3$
}

de Brix (Paraguay), Dra. Nadia de Araujo (Brasil), José $A$. Moreno Ruffinelli como quinto árbitro.

Dr. Ricardo Olivera integra este TPR ante la excusación do Abitro Titular do Uruguai Dr. Roberto Puceiro, e a Dra. Nadia de Araujo actúa ante la excusación do Dr. Joao Grandino Rodas, Árbitro Titular pela República Federativa do Brasil.

REPRESENTANTES LEGAIS: República Argentina. titular o Dr. Juan Vicente Sola e a Dra. Nora Capello como representante alterno.

\section{NORMATIVA APLICADA NO LAUDO:}

- Artigo 34 do Protocolo de Olivos ${ }^{2}$

- Artigo 20 do Protocolo de Olivos ${ }^{3}$

\begin{abstract}
${ }^{2}$ No qual estabelece: Direito aplicável 1. Os Tribunais arbitrais e o Tribunal Permanente de Revisão decidirão a controvérsia com base no Tratado de Assunção, o Protocolo de Ouro Preto, os protocolos e acordos celebrados dentro do marco do Tratado de Assunção, às Decisões do Conselho do Mercado Comum, as Resoluções do Grupo Mercado Comum e das Diretivas da Comissão de Comércio do MERCOSUL bem como os princípios e disposições de Direito Internacional aplicáveis à matéria. 2. A presente disposição não restringe a faculdade dos Tribunais Arbitrais Ad Hoc ou a do Tribunal Permanente de Revisão quanto atue na instância direta e única, conforme ao disposto no artigo 23 de decidir a controvérsia ex aequo et bono, se as partes assim concordarem. A partir da entrada em vigência do Protocolo Modificatório de Olivos, o seu conteúdo forma parte do Protocolo de Olivos e por tanto os países que se aderirem ao processo de integração pelo tratado de Assunção, também se aderem ipso iure ao Protocolo de Olivos modificado pelo mencionado Protocolo Modificatório.
\end{abstract}

${ }^{3}$ Funcionamento do Tribunal 1. Quando a controvérsia envolve a dois Estados Partes, o Tribunal estará integrado por três (3) árbitros. Dois (2) árbitros serão nacionais de cada Estado parte na controvérsia e o terceiro, que exercerá Presidência se designará, mediante sorteio a ser realizado pelo Diretor da Secretaria 


\title{
Série: Jurisprudência * LAUDOS N. ${ }^{\circ} 3$
}

\author{
- Artigo 17 do Protocolo de Olivos ${ }^{4}$ \\ - Artigo 10 de Protocolo de Olivos ${ }^{5}$
}

Administrativa do MERCOSUL, entre os árbitros restantes que não sejam nacionais dos Estados partes na controvérsia. A designação do Presidente será feita no dia seguinte ao da interposição do recurso de revisão, data a partir da qual ficará constituído o Tribunal a todos os efeitos. 2. Quando a controvérsia envolva a mais de dois Estados Partes o Tribunal Permanente de Revisão estará integrado por cinco (5) árbitros. 3. Os Estados Partes, de comum acordo, poderão definir outros critérios para o funcionamento do Tribunal estabelecido neste artigo.

${ }^{4}$ Determina que: 1. Quaisquer das partes na controvérsia poderá apresentar um recurso de revisão ao Tribunal Permanente de Revisão, contra o laudo do Tribunal Arbitral Ad Hoc no prazo não superior a quinze (15) dias a partir da notificação do mesmo. 2. O recurso estará limitado às questões de direito tratadas na controvérsia e às interpretações jurídicas desenvolvidas no laudo do Tribunal Arbitral Ad Hoc. 3. Os laudos dos Tribunais Ad Hoc ditados com base aos princípios ex aequo et Bono não serão suscetíveis de recursos de revisão. 4. A Secretaria Administrativa do MERCOSUL terá a seu cargo as gestões administrativas que sejam encomendadas para o desenvolvimento dos procedimentos e manterão informados os Estado Partes na controvérsia e ao Grupo Mercado Comum.

${ }^{5}$ Composição do Tribunal Arbitral Ad Hoc 1. O procedimento arbitral se substanciará perante um Tribunal Ad Hoc composto de três (3) árbitros. 2. Os árbitros serão designados da seguinte maneira: i) Cada Estado parte na controvérsia designará um (1) árbitro titular da lista prevista no Artigo 11.1, no prazo de quinze (15) dias, contados a partir da data que a Secretaria Administrativa do MERCOSUL tenha comunicado aos Estados partes na controvérsia a decisão de um deles de recorrer à arbitragem. Simultaneamente designará, da mesma lista, um (1) árbitro suplente para substituir o titular no caso de incapacidade ou desculpa deste em qualquer etapa do procedimento arbitral. ii) Se um dos Estados partes na controvérsia não for nomeado seus árbitros no prazo indicado no numeral 2 i), eles serão designados pelo sorteio, pela Secretaria Administrativa do MERCOSUL dentro do término de dois (2) dias, contado a partir do vencimento de aquele prazo, entre os árbitros deste Estado da lista prevista no Artigo 11.1. 3. (O árbitro Presidente será designado da seguinte maneira: i) Os Estados partes na controvérsia designarão de comum acordo ao terceiro árbitro, que presidirá o Tribunal Arbitral 


\section{Série: Jurisprudência * LAUDOS N. ${ }^{\circ} 3$}

- Artigo 20 da decisão MERCOSUR/CMC/DEC. $N^{\circ} 37 / 03$ Regulamento do Protocolo de Olivos para a Solução de Controvérsias no MERCOSUL ${ }^{6}$

Ad Hoc, da lista prevista no Artigo 11.2 iii), no prazo de quinze (15) dias, contado a partir da data pela qual a Secretaria Administrativa do MERCOSUL tenha comunicado aos Estados partes na controvérsia a decisão de um deles de recorrer à arbitragem. Simultaneamente designaram, da mesma lista, um árbitro suplente para mudar o titular no caso de incapacidade ou excusa deste em qualquer etapa do procedimento arbitral. O Presidente e seu suplente não poderão ser nacionais dos Estados partes na controvérsia. ii) Se não houver acordo entre os Estados partes na controvérsia para escolher o terceiro árbitro, dentro do prazo indicado, a Secretaria Administrativa do MERCOSUL, a pedido de qualquer deles, procederá a designá-lo pelo sorteio da lista do Artigo 11.2 iii), excluindo do mesmo aos nacionais dos Estados partes na controvérsia. iii) Os designados para atuar como terceiros árbitros deverão responder no prazo máximo de três (3) dias, contado a partir da notificação de sua designação, sobre sua aceitação para atuar numa controvérsia. 4. A Secretaria Administrativa do MERCOSUL notificará os árbitros a sua designação.

${ }^{6}$ Sorteio de árbitros (art. 10.2 ii, 10.3 ii PO) 1. Vencido o prazo para que um Estado designe o seu árbitro, o Diretor da SM procederá a efetuar de ofício o sorteio para o a sua nomeação. 2 . O sorteio do terceiro árbitro $\mathrm{O}$ sorteio do terceiro árbitro será efetuado pelo Diretor da SM a pedido de uma das partes. 3 . O sorteio será realizado dentro de três (3) dias de formulada à solicitação. A SM informará aos Estados Partes a data e a hora previstas para o sorteio. Os Estados-Partes poderão designar representantes para que assistam a este ato. Será deixada constância do atuado na ata que terá como conteúdo: a. lugar e data da realização do ato; b. nome e cargo dos presentes; c. nome dos candidatos que foram incluídos no sorteio; $d$. resultado do sorteio; e. firma dos presentes. 
Palavras Chave: Direito internacional, Integração regional, Recursos, Tribunal Permanente de Revisão, MERCOSUL, Liberdade de circulação, Cortes de rotas

\subsection{Apresentação}

Nesta oportunidade foi realizado um resumo sobre o Laudo do TPR $\mathrm{N}^{\circ}$ 2/2006 relativo ao recurso de revisão interposto pela República Argentina (em adiante, Argentina) contra uma decisão do Tribunal Ad Hoc de data de 21 de junho de 2006 no marco da controvérsia entre a República Argentina e a República Oriental do Uruguai (em adiante, Uruguai) relativo ao reclamo por parte do Uruguai com relação aos impedimentos à livre circulação derivada dos cortes no território argentino das vias de acesso aos portos internacionais Gral San Martín e Gral Artigas.

No reclamo original por parte do Uruguai está constituído pelos cortes, no território argentino, das rotas de acesso a pontes internacionais que comunicam com o Uruguai, dispostos pelos movimentos ambientalistas argentinos no protesto pela construção de plantas de celulose sobre o Río Uruguay que é limítrofe entre ambos os países. O Uruguai manifestava que as autoridades argentinas omitisses de tomar as medidas apropriadas para fazer cessar os cortes de rotas e que, tais cortes, ocasionaram importantes danos e prejuízos, também aos setores e agentes econômicos deste país, 


\section{Série: Jurisprudência * LAUDOS N. ${ }^{\circ} 3$}

fundamentalmente vinculados à negócios de exportação e importação, turismo e transporte terrestres de passageiros e mercadorias.

Durante o procedimento, a fase de conformação do TAH, a Argentina solicitou a suspensão das atuações. O Ministério de Relações Exteriores, comércio Internacional e Culto da República da Argentina tinha manifestado a sua desconformidade com o processo de designação do Terceiro Árbitro e apresenta um recurso de revisão. Trata-se de uma situação excepcional não prevista no Protocolo de Olivos e, em consequência o TPR, por maioria, argumentou que não era admissível a substância peticionada pela Parte Argentina, mas que sem o embargo, esta determinação não deixava a parte recorrente em estado indefeso, mas que meramente se declarava não admissível o recurso de revisão neste estágio processual, não emitindo juízo de valor sobre o mérito das alegações sustentadas pela parte argentina que, bem podia, ser novamente apresentada como conteúdo de um eventual recurso de revisão contra o laudo arbitral que pudesse, em definitiva, recair.

\subsection{Resumo técnico jurídico do Laudo}

\section{Questões analisadas:}

\section{1) Alegações da Argentina}

A República Argentina solicita que o TPR decrete a nulidade da designação efetuada do terceiro árbitro presidente do Tribunal e tenha por não constituído o Tribunal Arbitral Ad Hoc em virtude de 


\section{Série: Jurisprudência * LAUDOS N. ${ }^{\circ} 3$}

vícios e no procedimento de sorteio. Solicita além disso, que a gravidade institucional que supõe o caso e o efeito que pode causar sobre os futuros procedimentos, o Tribunal Permanente se reúna em pleno e que se determine a competência de decidir sobre todas as questões relativas à integração de um tribunal arbitral e não somente sobre os laudos definitivos.

\section{2) Conformação do TPR em pleno}

Diante do pedido da Argentina referente ao que o Tribunal seja conformado em plenário para resolver o recurso de revisão interposto, o TPR determina que essa possibilidade somente esteja prevista, em princípio, pelo protocolo de Olivos quando a controvérsia envolva a mais de dois Estados -Partes ${ }^{7}$. No caso analisado, este suposto não está dado, devido a que são as duas partes da controvérsia (Argentina e Uruguai). Não obstante, tal circunstância é devido ao tema sobre o qual versa o recurso, que se encontra estreitamente vinculado à competência do TPR, se decide abrir uma exceção, aceitar o recurso e resolvê-lo em plenário.

\footnotetext{
${ }^{7}$ No caso de que sejam 2 os Estados-Partes na controvérsia, o TPR deve estar conformado pelos três árbitros. Dois árbitros devem ser nacionais de cada Estado- Parte na controvérsia e o terceiro, que exercerá a presidência se designa, por sorteio a ser realizado pelo secretário da Secretaria do TPR (Aplicação do Protocolo de Olivos modificatório), entre os árbitros restantes que não sejam nacionais dos Estados-partes na controvérsia.
} 


\section{3) A possibilidade de pleitear um Recurso de Revisão às Resoluções dos TAH e as questões de Direito.}

Como foi introduzida na apresentação do presente resumo, a República Argentina pleiteou um recurso de revisão contra uma decisão do Tribunal Ad Hoc de data de 21 de junho de 2006. Tratar-se-ia, então, de determinar se o TPR tinha ou não a competência para conhecer nos recursos de revisão um questionamento a respeito de uma providência ou autos interlocutórios dos TAH. O TPR indicou, neste sentido, que, em primeiro momento, todo recurso de revisão pleiteado deve ter por objeto a impugnação de um laudo ditado por um TAH do MERCOSUL. Além disso, o TPR indicou que, ainda que tivesse sido aceita a competência, o recurso de revisão deveria estar vinculado e limitado às questões de direito e às interpretações jurídicas desenvolvidas no laudo de revisão.

Entende o TPR que este critério é condizente com o moderno conceito de arbitragem no qual se privilegia a maior simplicidade com que se desenvolve o procedimento e celeridade com que possa obter uma solução definitiva. Excluir toda classe de recursos contra as decisões diferentes do Laudo forma parte desta tessitura.

Cita o TPR, o caso do direito comunitário no qual os atos interlocutórios do Tribunal de Primeira Instancia não sejam recorríveis perante a instância superior. O que é recorrível são os autos destes tribunais que admitem ou deneguem medidas cautelares. 


\section{Série: Jurisprudência * LAUDOS N. ${ }^{\circ} 3$}

Neste sentido, sustenta o TPR que o Art. 17 do PO foi coerente com este critério de simplicidade ao ser feito recorrível somente os Laudos dos TAH.

\section{Decisão:}

Por maioria é declarada não admissível o recurso de revisão na etapa processual na qual foi pleiteado. Não obstante, o TPR esclarece que as alegações sustentadas pela parte argentina podem ser novamente pleiteadas perante um eventual recurso de revisão contra o laudo arbitral.

\section{Referências bibliográficas}

ESPASA CALPE. Diccionario jurídico Espasa. Madrid: Espasa Calpe, 2004

MERCOSUR. "Protocolo de Brasília"

MERCOSUR. "Protocolo de Olivos para la Solución de Controversias en el MERCOSUR"

MERCOSUR. "Protocolo de Ouro Preto"

MERCOSUR. "Tratado de Asunción

MERCOSUR. "Protocolo Modificatório do Protocolo de Olivos"

MERCOSUR. MERCOSUR/CMC/DEC No37/03: Regulamento do Protocolo de Olivos 


\section{Série: Jurisprudência * LAUDOS N. ${ }^{\circ} 3$}

MERCOSUR. MERCOSUR/CMC/DEC N N030/05: Regras de procedimento do TPR

TRIBUNAL PERMANENTE DE REVISÃO: Laudo do Tribunal permanente de Revisão constituído em plenário para entender um recurso de revisão apresentado pela República Argentina contra a decisão do TAH de 21 de junho de 2006 na controvérsia promovida pela República Oriental do Uruguai contra a República Argentina sobre "impedimentos à livre circulação derivado dos cortes no território argentino das vias de acesso às pontes internacionais Gral. San Martín e Gral Artigas." Disponível em:

\section{https://www.tprmercosur.org/pt/docum/laudos/Laudo}

\section{6 pt.pdf}

\section{Guia de bibliografia complementar $^{8}$}

AMZEL de GINZBURG, Clara. "Uruguay-Argentina: impedimentos a la libre circulación". Em: Cienfuegos Mateo, Manuel (ed.). Los cambios en la infraestructura regional y sus impactos ambientales en clave de mejorar la gobernabilidad en el Mercosur". Argentina, Córdoba: Lerner Editora, 2011. Cap. XIII. p. 323-338.

Disponível em:

\section{https://core.ac.uk/download/pdf/296392755.pdf}

${ }^{8}$ Considerando a importância que há no tema tratado no laudo, é incluída na bibliografia complementar títulos e trabalhos realizados sobre o caso perante a Corte Internacional da Haia e o falho do Tribunal Ad Hoc do MERCOSUL de setembro de 2006. 


\section{Série: Jurisprudência * LAUDOS N. ${ }^{\circ} 3$}

ARBUET-VIGALI, Heber y VIGNALI GIONANETTI, Daniel. "Corte Internacional de Justicia Caso no 135. Caso de las fábricas de pasta de celulosa sobre el Río Uruguay Argentina con Uruguay. Fallo del 20 de abril de 2010". Revista Prismas: Direito, Políticas Públicas e Mundialização, 2011. vol. 8, $\mathrm{N}^{\circ}$ 1. DOI: .10.5102/prismas.v8i1.1192. Disponível em https://www.publicacoes.uniceub.br/prisma/article/view /1192/1132

BERTONI, Liliana. Las papeleras en cuestión: Un recorrido por el derecho ambiental e internacional de La Haya al Mercosur. Buenos Aires: Eudeba, 2010

GAJATE, Rita M. "Una conflictiva cuestión medioambiental subregional: el caso de las pasteras". Em: Cienfuegos Mateo, Manuel (ed.). Los cambios en la infraestructura regional $y$ sus impactos ambientales en clave de mejorar la gobernabilidad en el Mercosur". Argentina, Córdoba: Lerner Editora, 2011, Cap. XII. p. 295-321. Disponível em https://core.ac.uk/download/pdf/296392755.pdf

GAJATE, Rita M. El conflicto de las pasteras. Los pronunciamientos de la Corte Internacional de Justicia y del Tribunal Ad Hoc del MERCOSUR. En: HUMMER, Waldemar (ed.) y MELLADO, Noemí - (ed. coord). "Cooperación y Conflicto en el MERCOSUR". Argentina, Córdoba: Lerner Editora. 2007. p.159-181

IRIART, María Sol. La constitución de un Tribunal de Justicia Supranacional para la solución de controversias en el Mercosur. Repositorio Universidad Siglo21.

Disponível

em:

https://repositorio.uesiglo21.edu.ar/bitstream/handle/u 
Série: Jurisprudência * LAUDOS N. ${ }^{\circ} 3$

es21/10869/Iriart\%2C\%20Mar\%C3\%ADa\%20Sol.pdf? sequence $=1$ \&isAllowed $=\mathrm{y}$

NOSCHANG, Patrícia Grazziotin. "O caso das papeleras na Corte Internacional de Justiça: direito ambiental versus direito econômico?" En: Menezes, Wagner (coord.) Estudos de direito internacional: Anais do $5^{\circ}$ Congresso brasileiro de direito internacional-2007. Vol XI. p. 215-223.

PASTORI FILLOL, Alejandro. "La continuación de los cortes de rutas en Territorio argentino y el problema de la ejecución de los laudos arbitrales del Mercosur". Revista de la Facultad de Derecho. 2006 n. ${ }^{\circ}$ 25, p. 239-257.

Disponível

em:

https://revista.fder.edu.uy/index.php/rfd/article/view/17 $\underline{3 / 178}$

PEREZ GUEDES, Agostina. "La política exterior argentina (2003-2011) ante el conflicto de papeleras. Un estudio de caso a partir del modelo de actor racional de Graham Allison". (Tesis de licenciatura). Directora. María Eugenia Renis. Universidad Nacional del Centro de la provincia de Buenos aires. Facultad de Ciencias Humanas. Licenciatura en Relaciones Internacionales, s/d.

Disponível

em

https://www.ridaa.unicen.edu.ar/xmlui/bitstream/handl e/123456789/1958/PEREZ\%20GUEDES\%2C\%20AG OSTINA.pdf? sequence $=1 \&$ isAllowed $=y$

REY CARO, Ernesto J. La controversia entre la República Argentina y la República Oriental del Uruguay sobre "las pasteras" en el ámbito del Mercosur. El laudo del Tribunal Ad Hoc de septiembre de 2006. UNAM: Biblioteca Jurídica Virtual del 
Série: Jurisprudência * LAUDOS N. ${ }^{\circ} 3$

Instituto de Investigaciones Jurídicas. p. 425-429.

Disponível

em:

https://archivos.juridicas.unam. mx/www/bjv/libros/6/25

52/21.pdf 


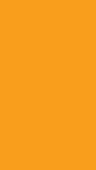

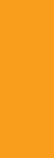

(1)

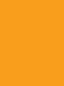

